\title{
Reducing Fetal Deaths in Multiple Births: Optimal Birthweights and Gestational Ages for Infants of Twin and Triplet Births *
}

\section{B. Luke}

Department of Obstetrics and Gynecology, University of Michigan Medical School, Ann Arbor, Michigan, USA.

\begin{abstract}
The objective of this study was to determine the birthweight and gestational age associated with the lowest fetal mortality for twins and triplets. The study design was a population-based analysis of all live births and fetal deaths in the US between 1983-88. Fetal mortality was compared by categories of birthweight and gestational age, for twins and triplets versus singletons, and within each plurality by the lowest rate compared to all other rates as relative risks $\pm 95 \% \mathrm{Cls}$. The overall versus lowest fetal death rate per 1,000 conceptions for singletons was 4.3 versus 0.9 at $3700-4000 \mathrm{~g}$ and $40-41$ weeks; for twins, 15.5 versus 3.3 at $2500-2800 \mathrm{~g}$ and 36-37 weeks; and for triplets, 21.0 versus 5.2 at $1900-2200 \mathrm{~g}$ at 34-35 weeks. Beyond these plurality-specific lowest ranges, the risk of fetal death increased, more for twins than singletons, and most for triplets. To conclude, fetal death rates can be reduced by $75-80 \%$ with attainment of birthweight and gestational age within a plurality-specific ideal range.
\end{abstract}

Key words: Fetal death, IUGR, Twins, Triplets

\section{INTRODUCTION}

An estimated 5.3 million women in the United States, or $9.1 \%$ of all women of reproductive age, have impaired fecundity [28]. Most infertility treatments carry a substantial risk of resulting in a multiple birth, ranging from $20-30 \%$ depending on the method $[22,23]$. In a national survey of families with triplet births, $50 \%$ had resulted from ovulation stimulating drugs and $9 \%$ from in vitro fertilization and gamete intrafallopian transfer [5]. Data from the annual survey of US programs offerring assisted repro-

* Presented at the 16th Annual Meeting of the Society of Perinatal Obstetricians, Kona, Hawaii, February, 1996. 
ductive technology procedures indicates that, of the resulting pregnancies, the proportion of multiple births ranged from $25 \%$ twins, $4.8 \%$ triplets, and $0.2 \%$ higher order multiples from in vitro fertilization; $27 \%$ twins, $6.6 \%$ triplets, and $0.3 \%$ higher order multiples from gamete intrafallopian transfer; $28.6 \%$ twins, and $4.4 \%$ triplets from zygote intrafallopian transfer; and $31.4 \%$ twins, and $5.7 \%$ triplets from donor oocytes [22].

There has also been a trend in the United States of postponing childbearing, with multiple births occurring more frequently among older mothers. Between 1970 and 1994, among women aged 30 and older, the proportion of first births increased from 5\% to $21 \%$, and the proportion of all births increased from $16 \%$ to $34 \%[24,26]$. As the result of these two factors, infertility treatments and a trend towards delaying childbearing, the incidence of multiple births has risen dramatically in the United States since the mid-1970s [14]. In 1994, the most current year for which statistics are available, there were 101,658 live infants in multiple births in the United States, the highest number ever recorded in the history of the vital statistics system [26]. As a result, the frequency of twins has increased from 1:48 births in 1985 to $1: 40$ births in 1994, and the frequency of triplet and higher order births has increased from 1:1912 in 1985 to 1:838 births in 1994 $[25,26]$. Multiple births are at high risk for antenatal complications $[7,9]$, including fetal death of one or more siblings [2]. The purpose of this investigation is to estimate the birthweight and gestational age associated with the lowest fetal death rate for infants of multiple births.

\section{MATERIAL AND METHODS}

The data used was the computerized certificates of all live births and all fetal deaths in the United States between 1983 and 1988, obtained from the National Center for Health Statistics. Live births and fetal deaths were categorized as singleton, twin, or triplet and higher order (triplets). Weeks' gestation was calculated from the last menstrual period and categorized into two-week intervals, limited to births occurring between 24-44 weeks. Birthweight was categorized into 300 -gram intervals, and limited to infants with birthweights between 500-6,000 grame.

The data was cleaned to eliminate live births and fetal deaths with biologically implausible birthweight-gestational age combinations using a generally accepted technique for vital statistics data $[4,27,30]$. It is well known that a substantial portion of births before 37 weeks' gestation have reported gestational ages that are in error by 4-20 weeks $[4,27,30]$. When plotted at each week of gestation below 37 weeks, the birthweight distribution is generally bimodal. The consensus of researchers is that the first mode (at the lower birthweight) represents the "true" mode, or births with accurately reported gestational ages. Since the birthweight distribution at each gestational week is symmetrical $[4,27]$, a smoothed curve eliminating the second mode more accurately represents biologically plausible birthweights for gestational age. For each plurality type this was done by eliminating all live births and fetal deaths beyond two standard deviations from the mean of live births within each two-week gestational age period. This resulted in less than a $2 \%$ reduction in fetal deaths and live births from the original study population. The final study sample included for singletons: $19,468,170$ live births and 
83,263 fetal deaths; for twins: 352,629 live births and 5,467 fetal deaths; and for triplets: 9,523 live births and 204 fetal deaths.

The analysis was conducted in several steps. First, the cumulative percent distribution of live births and fetal deaths was described by plurality, birthweight, and gestational age, and the $50 \%$ distribution determined for each. Second, within each plurality category, fetal death rates were calculated as fetal deaths per 1,000 conceptions (fetal deaths/[fetal deaths + live births] x 1,000) overall and for each category of birthweight, gestational age, and birthweight and gestational age. For each plurality type, the lowest fetal death rate was identified within the categories of birthweight, gestational age, and birthweight and gestational age. Third, within each category, the lowest fetal death rate was assigned a relative risk (RR) of 1.0 and all other rates within each category compared to this lowest rate, as RRs $\pm 95 \%$ confidence intervals (Cls). Exact two-sided probabilities were calculated using Fisher's Exact Test for this and subsequent analyses because of the small numbers within some cells for triplets. Fourth, RRs $\pm 95 \%$ Cls were calculated by comparing birthweight-, gestational age-, and birthweight and gestational age-specific rates for twins versus singletons, and for triplets versus singletons. Fifth, the overall and lowest fetal death rates by categories of birthweight ("ideal birthweight"), gestational age ("ideal gestational age"), and birthweight and gestational age ("ideal birthweight and gestational age") were compared for twins versus singletons, and for triplets versus singletons as RRs $\pm 95 \%$ Cls.

\section{RESULTS}

Based on the cumulative percent distribution by plurality, birthweight, and gestation, $50 \%$ of live births among singletons were less than 3100-3400 g and 38-39 weeks, compared to twins at 2200-2500 $\mathrm{g}$ and 35-36 weeks, and triplets at 1600-1900 $\mathrm{g}$ and 32-33 weeks. Fifty percent of fetal deaths among singletons were less than 1900-2200 g and 34-35 weeks, compared to twins at 1300-1600 g and 33-34 weeks, and triplets at 1000-1300 g and 31-32 weeks. The distribution of fetal deaths suggests a common factor of growth retardation for all pluralities, and a narrower range of birthweights (1000-2200 g) and gestational ages (31-35 weeks) than for live births (1600-3400 g and 32-39 weeks). Among live births, the distributions of birthweights and gestational ages of twins showed a downwards shift after 35 weeks' gestation, suggesting a slowing of growth. For triplets, this deviation occurred earlier, at about 30-32 weeks.

The lowest fetal death rate per 1,000 conceptions for singletons was 4.3 overall, 1.0 by birthweight alone (3700-4000 g), 1.6 by gestational age alone ( $40-41$ weeks), and 0.9 by birthweight and gestational age (3700-4000 $\mathrm{g}$ at 40-41 weeks) (Table 1). Among twins, the lowest fetal death rate per 1,000 conceptions was 15.5 overall, 4.7 by birthweight alone (2500-2800 g), 8.1 by gestational age alone (36-37 weeks), and 3.3 by birthweight and gestational age (2500-2800 g at 36-37 weeks) (Table 2). Among triplets, the lowest fetal death rate per 1,000 conceptions was 21.0 overall, 9.3 by birthweight alone ( $1900-2200 \mathrm{~g}), 11.4$ by gestational age alone ( $34-35$ weeks), and 5.2 by birthweight and gestational age (1900-2200 at 34-35 weeks) (Table 3).

Assigning the lowest fetal death rate by birthweight alone, gestational age alone, and birthweight and gestational age a relative risk (RR) of 1.0, all other categories of birth- 

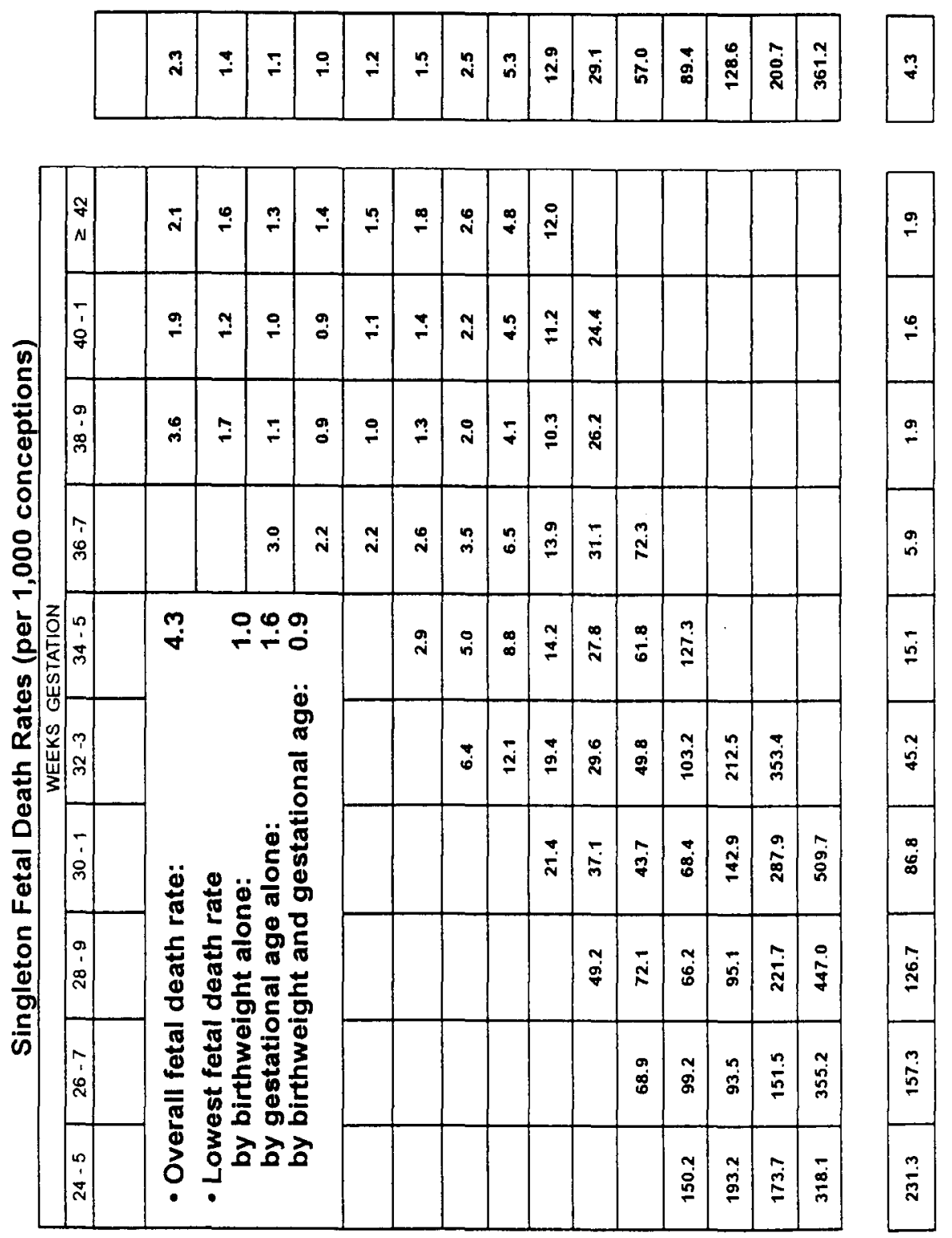

Dิ 

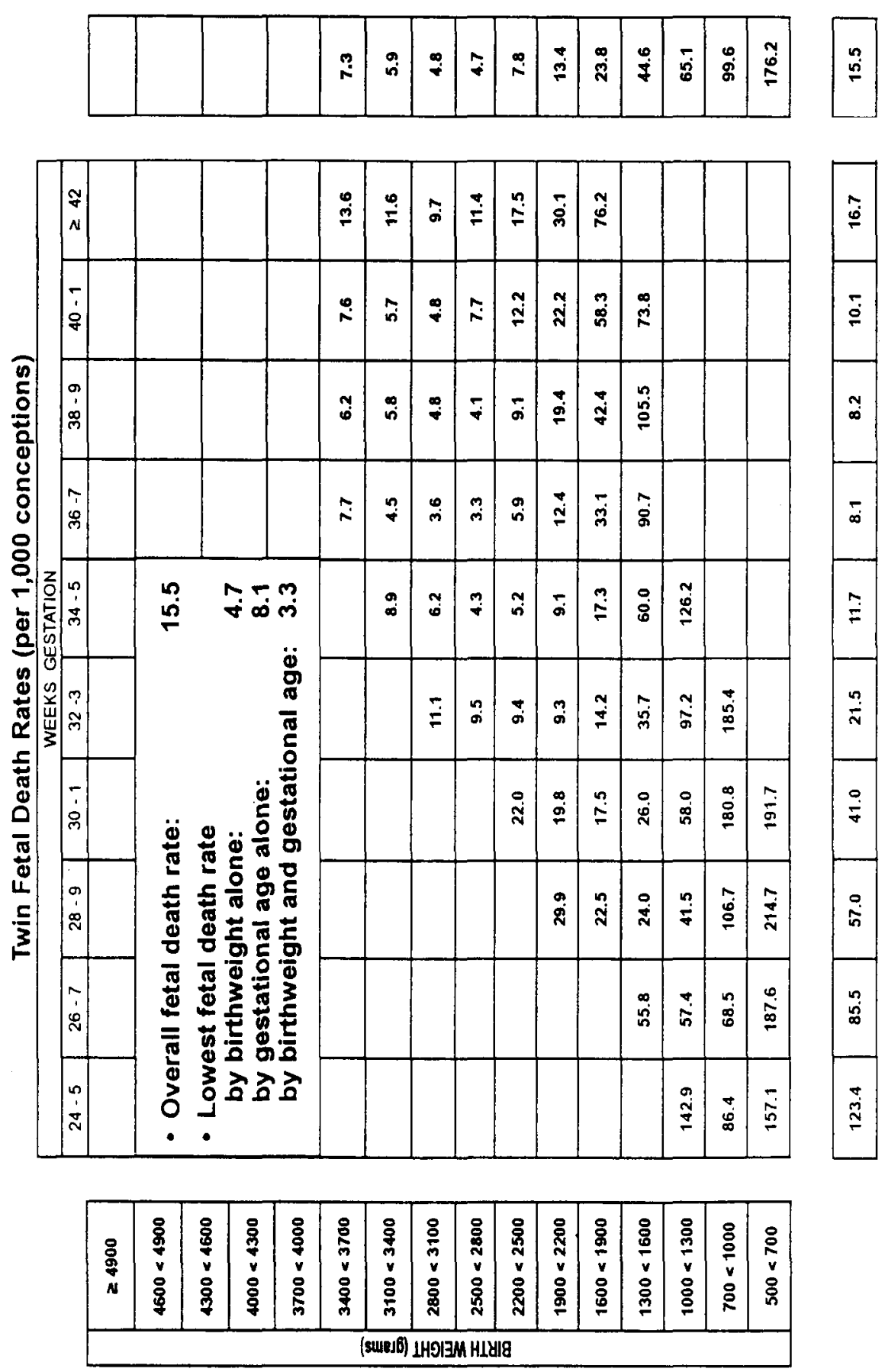

 

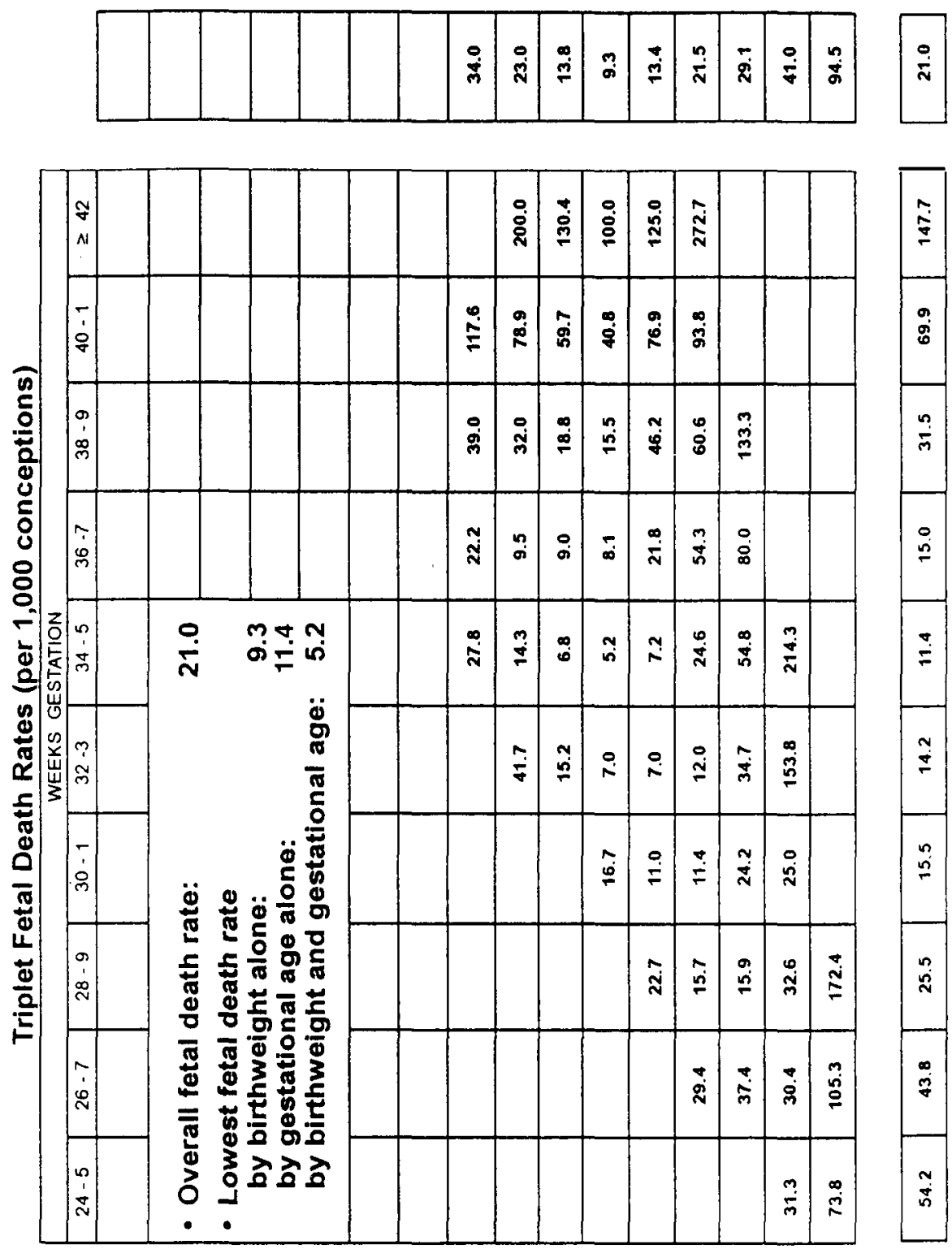
weight, gestational age, and birthweight and gestational age were then compared to these lowest rates, as RRs $\pm 95 \%$ confidence intervals (Cls). Among singletons, the lowest fetal death rate occurred at 3700-4000 g and 40-41 weeks, although the risk of fetal death was not significantly different at 3700-4000 $\mathrm{g}$ and 38-39 weeks, nor at 4000-4300 $\mathrm{g}$ and $40-41$ weeks (Table 4). Beyond these three birthweight and gestational age categories, the risk of fetal death increased significantly, generally increasing by $20 \%$ (RR 1.2) two weeks above and two weeks below the $40-41$ week ideal. By birthweight, the risk of fetal death increased 40-50\% (RR 1.4-1.5) $600 \mathrm{~g}$ above and below the ideal of $3700-4000 \mathrm{~g}$. Beyond these ranges, the risk of fetal death steadily increased with each lower category of birthweight, gestational age, or both. Before 35 weeks' gestation, within birthweight and gestational age categories, the highest risks for fetal death were among the lowest birthweight categories, suggesting a strong association between intrauterine growth retardation and fetal demise. Before 35 weeks' gestation, the lowest birthweights still had the highest risks of fetal death, but the risks at all categories of birthweight were significantly elevated due to the added effects of immaturity. Generally, intrauterine growth retardation was a greater factor for fetal death than immaturity, with a larger increase in risk across birthweights at a given gestational age than across gestational ages at a given birthweight. For example, for infants with birthweights of 2200-2500 g, the risk of fetal death increased 1.6-fold from 32-33 weeks to $\geq 42$ weeks, whereas at 34-35 weeks' gestation, the risk of fetal death increased 25.2-fold across birthweights of $1300-1600 \mathrm{~g}$ to $2800-3100 \mathrm{~g}$.

Among twins, the lowest fetal death rate occurred at $2500-2800 \mathrm{~g}$ and $36-37$ weeks, although the risk of fetal death was not significantly different at $2500-2800 \mathrm{~g}$ and either 34-35 weeks or 38-39 weeks, nor at 36-37 weeks at birthweights of 2800-3400 g (Table $5)$. Beyond these five birthweight-gestational age categories, the risk of fetal death increased significantly, by 30-50\% (RR 1.3-1.5) two weeks above and two weeks below the ideal of 36-39 weeks, and by 60-70\% (RR 1.6-1.7) $600 \mathrm{~g}$ above and $300 \mathrm{~g}$ below the ideal of 2500-3100 g. Beyond these ranges, the risk of fetal death increased with each category decrease in birthweight, gestational age, or both. The increase in risk with each category deviation from the ideal was greater for twins than singletons. For example, at $600 \mathrm{~g}$ below the plurality-specific ideal birthweight and gestational ages, the risk of fetal death was $1.5(95 \% \mathrm{Cl}, 1,4,1.6)$ for singletons compared to $3.7(2.8,4.9)$ for twins; at $900 \mathrm{~g}$ below the respective ideals, the risk was $2.4(2.2,2.6)$ for singletons compared to $10.1(7.7,13.4)$ for twins. As seen in singletons, the highest rates of fetal death within each gestational age category were among the lowest birthweight categories. Also among twins, intrauterine growth retardation was a greater factor for fetal death than immaturity, with a larger increase in risk across birthweights for a given gestational age than across gestational ages for a given birthweight. Using the same ranges as discussed for singletons above, at birthweights of 2200-2500 g, the risk of fetal death increased 1.9-fold from $32-33$ weeks to $\geq 42$ weeks, compared to the 10.5 -fold increased risk for infants born at 34-35 weeks with birthweights of 2800-3100 g to $1300-1600 \mathrm{~g}$. By gestational age alone, the risk of fetal death for twins beyond 39 weeks' gestation increased significantly, with RRs of $1.3(1.1,1.4)$ at $40-41$ weeks and $2.1(1.8,2.4)$ at $\geq 42$ weeks. When this twin-specific range of maturity was combined with intrauterine growth retardation (i.e., birthweights below $2200 \mathrm{~g}$ after 37 weeks' gestation), there was a doubling and tripling of RRs with each category decrease in birthweight. 

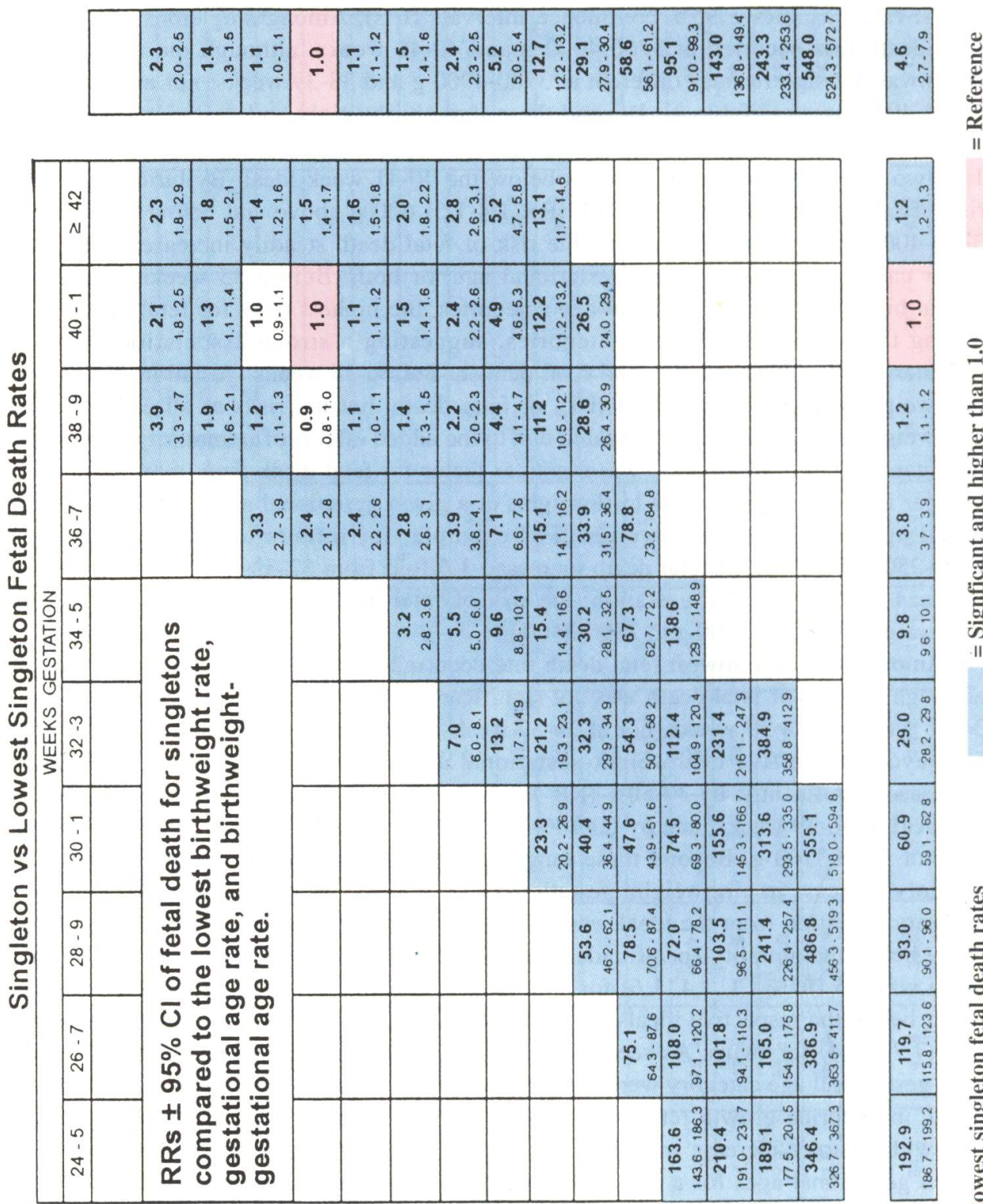

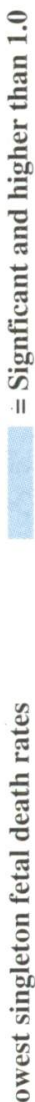

\begin{tabular}{|c|c|c|c|c|c|c|c|c|c|c|c|c|c|c|c|}
\hline $\begin{array}{l}\text { ठ } \\
\text { \% } \\
\text { N }\end{array}$ & 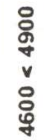 &  & 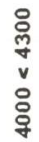 & $\begin{array}{l}\text { ¿ } \\
\stackrel{+}{+} \\
v \\
\stackrel{0}{0}\end{array}$ & $\begin{array}{l}\stackrel{8}{0} \\
\text { m } \\
v \\
\stackrel{0}{0}\end{array}$ & $\begin{array}{l}\stackrel{े}{+} \\
\text { m } \\
v \\
\stackrel{े}{0}\end{array}$ & 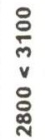 & 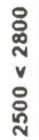 & 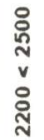 & $\begin{array}{l}\text { ָิ } \\
\text { v } \\
\text { \& } \\
\text { ᄋ్ }\end{array}$ & 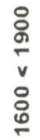 & 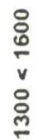 & 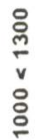 & 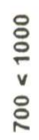 & $\begin{array}{l}\stackrel{8}{尺} \\
v \\
\stackrel{8}{\circ}\end{array}$ \\
\hline
\end{tabular}

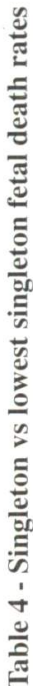



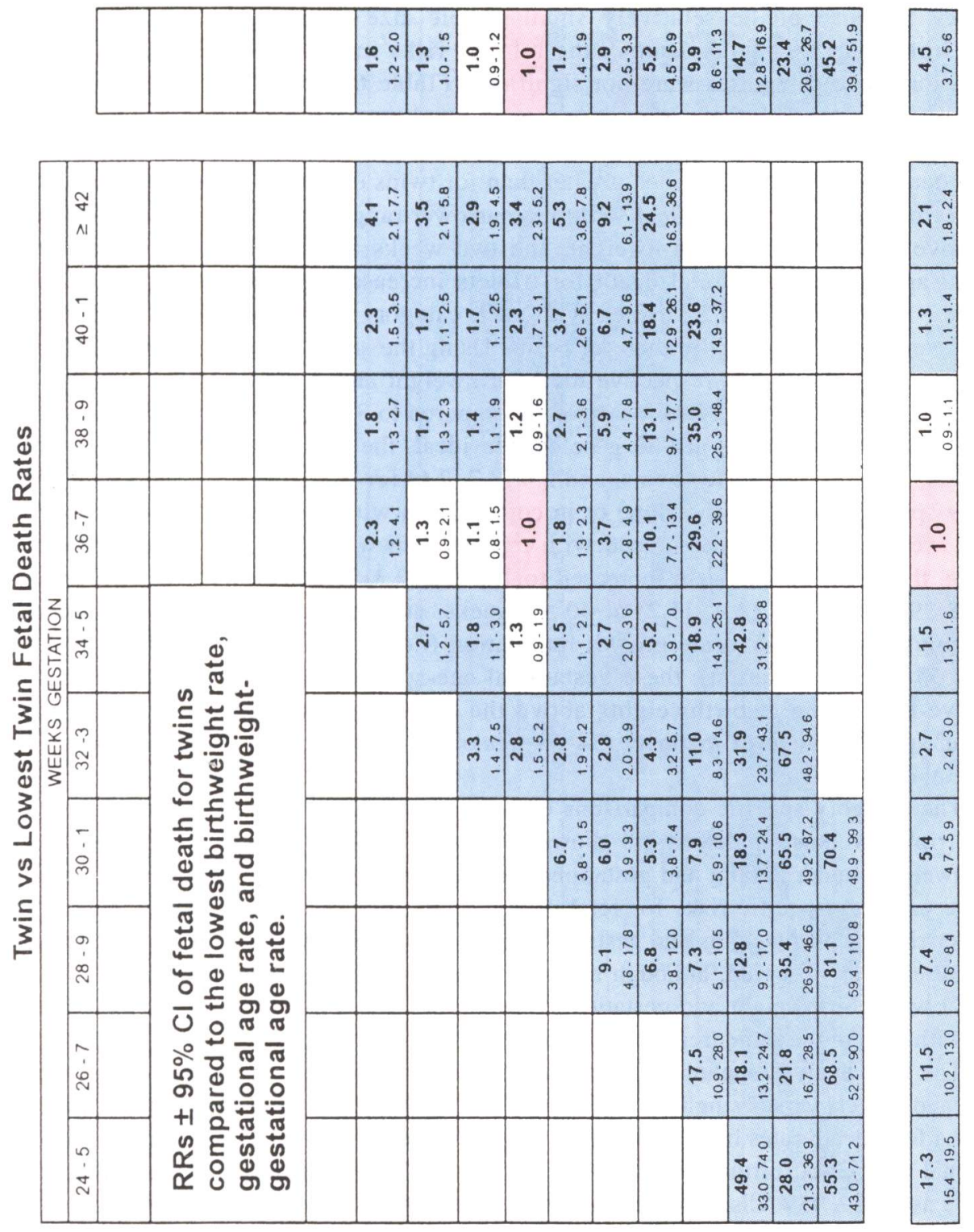

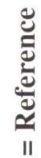

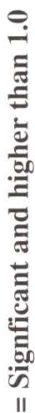

\begin{tabular}{|c|c|c|c|c|c|c|c|c|c|c|c|c|c|c|c|}
\hline 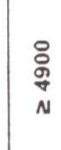 & 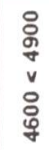 & $\begin{array}{l}\text { Oे } \\
\text { Q } \\
\text { v } \\
\text { oे } \\
\text { Vे }\end{array}$ & 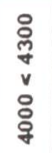 & 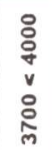 & $\begin{array}{l}\text { ¿ } \\
\text { p } \\
\text { v } \\
\text { o } \\
\text { dे }\end{array}$ & 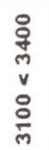 & 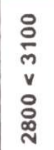 & 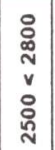 & $\begin{array}{l}\text { ㅇ․ } \\
\text { vv } \\
\text { ¿ें }\end{array}$ & 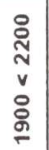 & 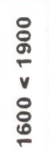 & 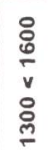 & 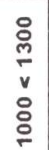 & 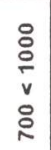 & $\begin{array}{l}\stackrel{8}{0} \\
v \\
\stackrel{े}{\circ}\end{array}$ \\
\hline
\end{tabular}

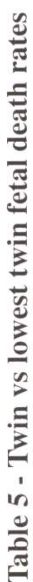


Among triplets, the lowest fetal death rate occurred at 1900-2200 $\mathrm{g}$ and 34-35 weeks. Because of the relatively small sample size of triplets $(9,523$ infants of live births and 204 fetal deaths), the relative risks in $35 \%$ of the birthweight and gestational age categories were not significant (Table 6). Despite this limitation, the magnitude of the relative risks across gestational ages, birthweights, and by both, show a pattern consistent with those of singletons and twins. Generally, the risk of fetal death for triplets was much greater than for twins or singletons at the same deviation from each plurality's ideal. Within a narrower range around the ideal (about 300 $\mathrm{g}$ above and below ideal birthweight, and two weeks above and below ideal gestational age), the risk of fetal death for triplets increased by $30-40 \%$. Beyond these ranges, the risk doubled or tripled with each category of birthweight or gestational age, even more dramatically than for twins. Using the same example as above, at 600 $\mathrm{g}$ below each plurality's respective ideal birthweight and gestational age, the risk of fetal death was $4.7(1.3,17.4)$ for triplets, compared to $3.7(2.6,5.1)$ for twins, and 1.5 $(1.4,1.6)$ for singletons; at $900 \mathrm{~g}$ below the ideal, the risk was $10.5(2.7,41.0)$ for triplets, $10.1(7.7,13.4)$ for twins, and $2.4(2.2,2.6)$ for singletons. The effects of plurality-specific postmaturity, alone or in combination with intrauterine growth retardation, were even more pronounced with triplets than with twins. By gestational age alone, the RRs of fetal death increased to $1.3(0.8,2.3)$ at $36-37$ weeks, $2.8(1.5,4.9)$ at $38-39$ weeks, $6.1(3.4,11.2)$ at $40-41$ weeks, and $13.0(6.9,24.3)$ at $\geq 42$ weeks. Combined with intrauterine growth retardation (i.e., birthweights of $1900 \mathrm{~g}$ or less after 35 weeks' gestation), these gestational age-specific risks increased by three-to twelve-fold. Even at birthweights above the ideal, at gestational ages beyond the triplet-specific range of maturity (34-35 weeks), there was a threefold increased risk of fetal death.

The category-specific comparisons of fetal death rates for twins versus singletons and triplets versus singletons are shown in Table 7 and 8 , respectively. Generally, at birthweights under $2800 \mathrm{~g}$ and gestational ages below 35 weeks, twins had significantly lower category-specific risks for fetal death compared to singletons, and significantly higher risks at birthweights and gestational ages above these ranges. For triplets, a similar pattern was observed, although the cutoffs were at $2200 \mathrm{~g}$ and 33 weeks, and there was a wider birthweight and gestational age transitional range that was not significant, but with RRs in the same trend.

The final analysis included a comparison of fetal death rates for twins versus singletons and triplets versus singletons at overall fetal death rates, and at the plurality-specific lowest fetal death rates by birthweight ("ideal birthweight"), gestational age ("ideal gestational age"), and birthweight and gestational age ("ideal birthweight and gestational age") as RRs $\pm 95 \%$ Cls. Overall, the RR of fetal death was $3.6(3.5,3.6)$ for twins compared to singletons, and $4.9(4.7,5.1)$ for triplets compared to singletons. At the plurality-specific ideal birthweight, the RR of fetal death was $4.6(4.1,5.1)$ for twins compared to singletons and $9.1(5.6,14.6)$ for triplets compared to singletons. At the plurality-specific ideal gestational age, the RR of fetal death was $5.1(4.8,5.6)$ for twins compared to singletons and $7.3(5.0,10.6)$ for triplets compared to singletons. At the plurality-specific ideal birthweight and gestational age, the RR of fetal death was 3.7 (2.9, 4.6) for twins compared to singletons and $5.7(2.1,15.2)$ for triplets compared to singletons. 
Reducing Fetal Deaths among Twins and Triplets 343
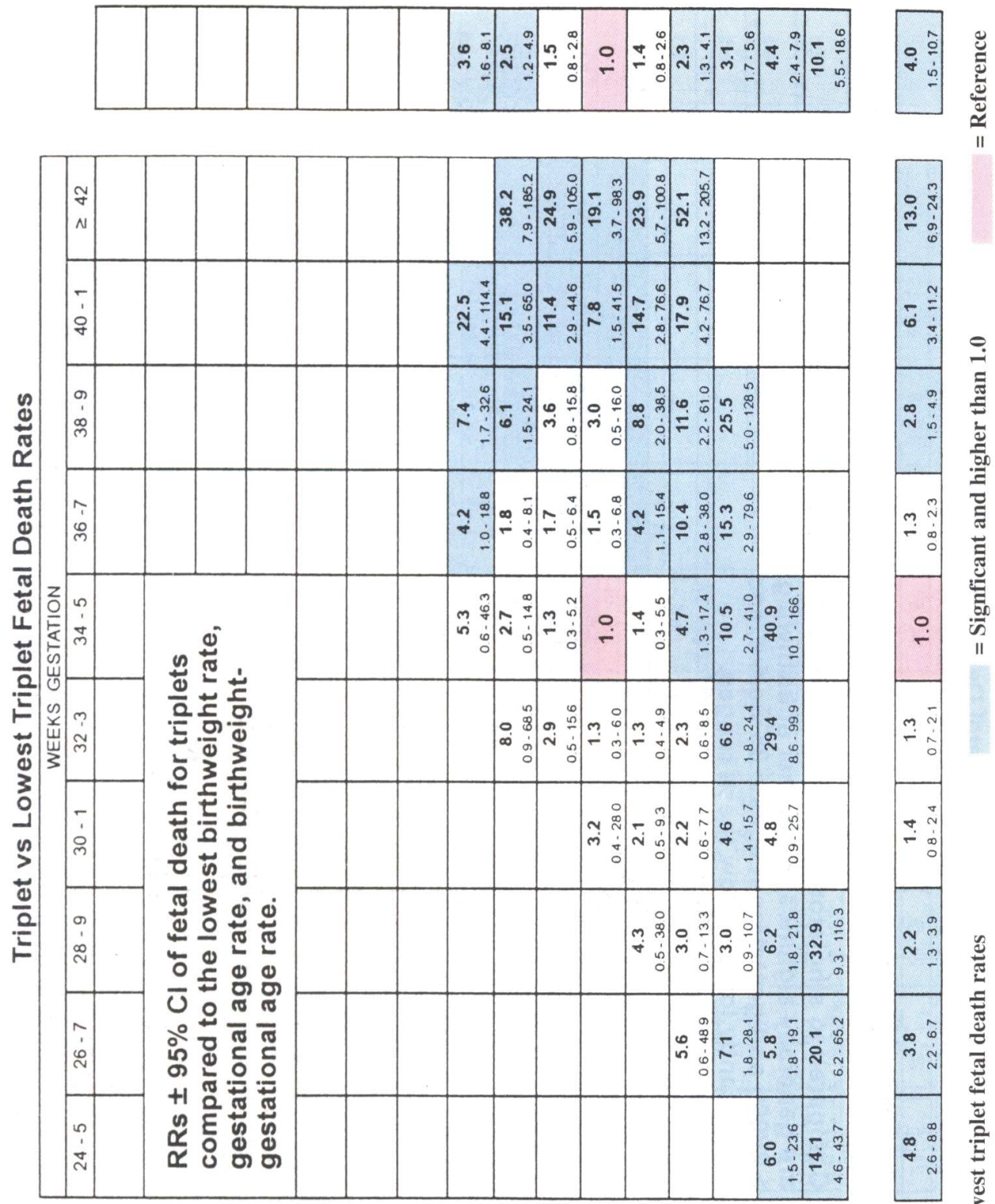

हี

\begin{tabular}{|c|c|c|c|c|c|c|c|c|c|c|c|c|c|c|c|}
\hline 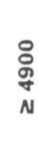 & 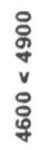 & 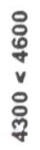 & 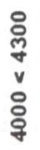 & 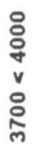 & 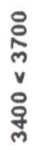 & $\begin{array}{l}\text { \& } \\
\text { के } \\
\text { v } \\
\text { \& } \\
\text { ळे }\end{array}$ & 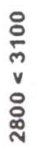 & 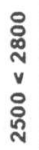 & 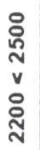 & 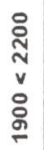 & $\begin{array}{l}\stackrel{8}{\circ} \\
\frac{\sigma}{v} \\
\stackrel{0}{\circ} \\
\stackrel{\circ}{-}\end{array}$ & $\begin{array}{l}\text { ¿ } \\
\stackrel{0}{0} \\
\text { v } \\
\stackrel{-}{-}\end{array}$ & $\begin{array}{l}\text { ¿ } \\
\frac{m}{v} \\
\text { v } \\
\text { ¿े }\end{array}$ & 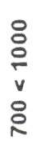 & 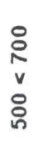 \\
\hline
\end{tabular}

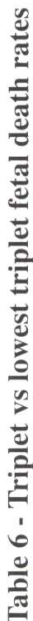



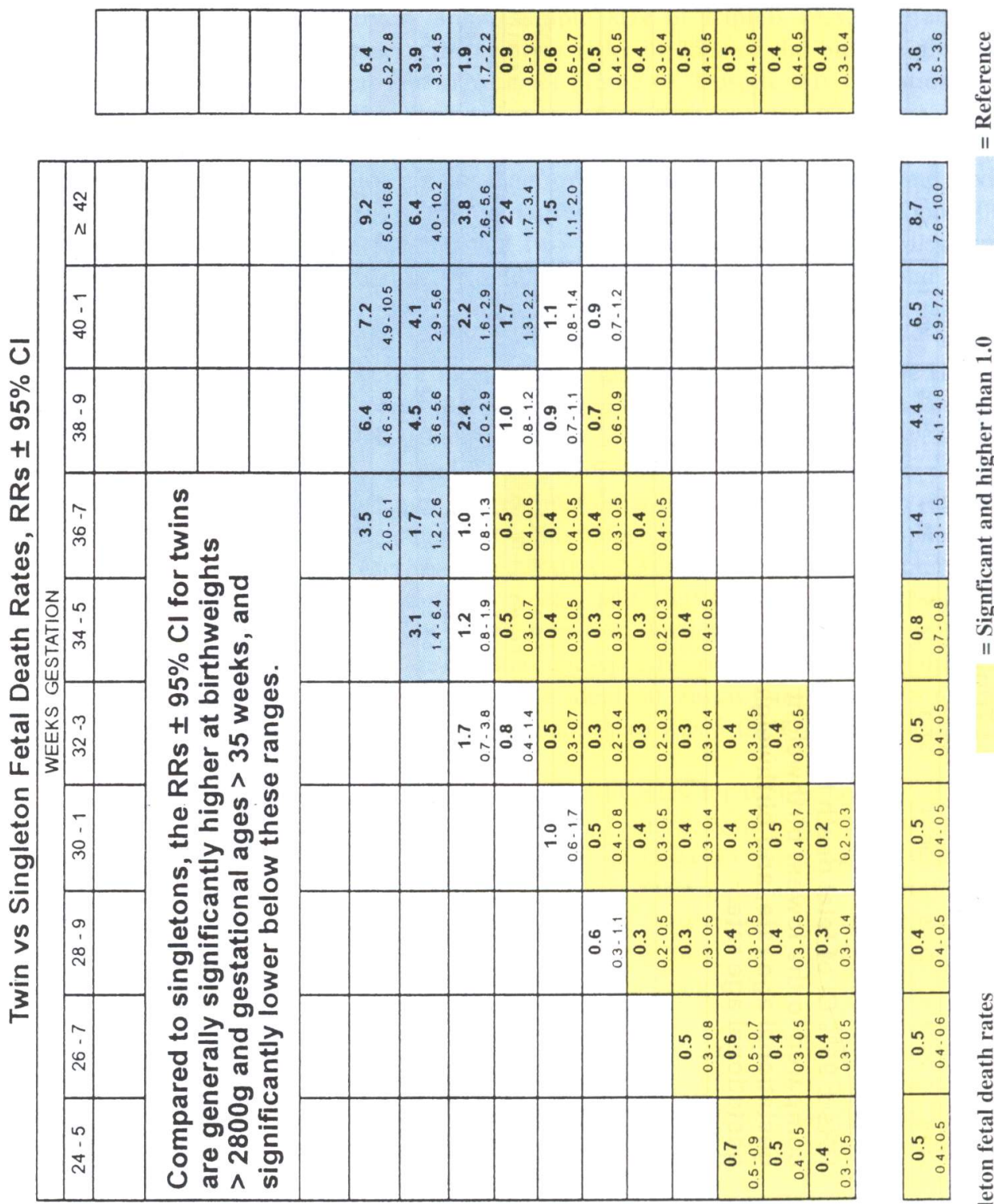

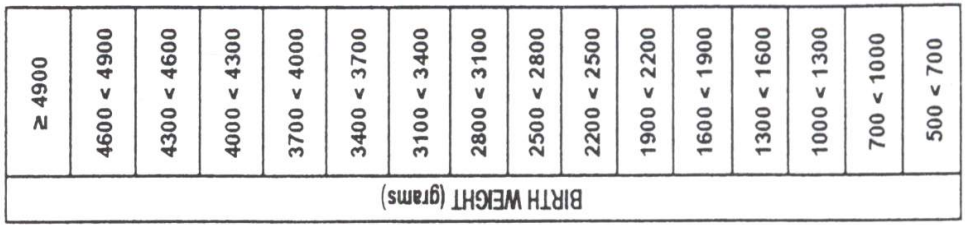

: 

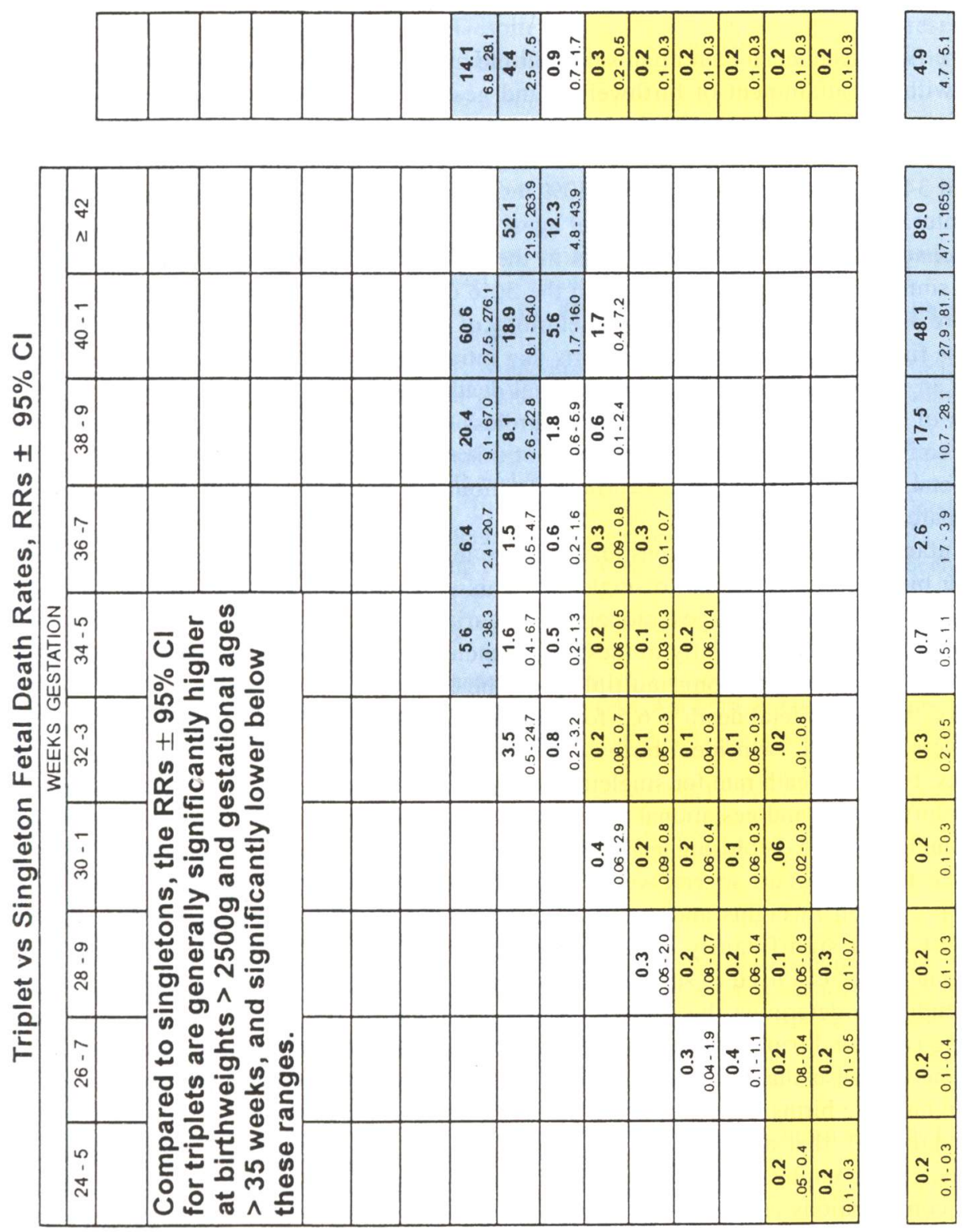

\begin{tabular}{|c|c|c|c|c|c|c|c|c|c|c|c|c|c|c|c|}
\hline $\begin{array}{l}\text { ○े } \\
\text { \%़े } \\
\text { N }\end{array}$ & 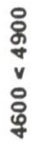 & 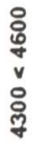 & 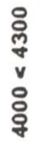 & 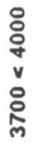 & 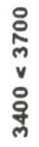 & $\begin{array}{l}\text { O } \\
\text { gे } \\
\text { v } \\
\stackrel{\circ}{\circ}\end{array}$ & 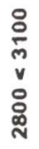 & 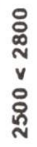 & $\begin{array}{l}\text { 尺 } \\
\text { సે } \\
v \\
\text { ¿ } \\
\text { స్ }\end{array}$ & 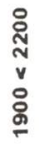 & 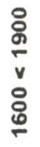 & 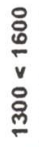 & 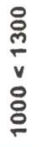 & $\begin{array}{l}\text { ㅇ } \\
\text { v } \\
\text { v } \\
\stackrel{0}{0}\end{array}$ & $\begin{array}{l}\text { ¿ } \\
\text { v } \\
\text { ¿ }\end{array}$ \\
\hline \multicolumn{16}{|c|}{ 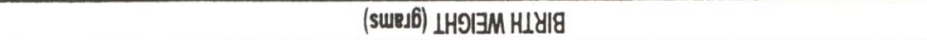 } \\
\hline
\end{tabular}

है 


\section{COMMENT}

These findings indicate that infants of multiple births are at increased risk for fetal death, but with the attainment of birthweight and gestational age within a plurality-specific ideal range, these risks can be dramatically reduced. The fetal death rate at $3700-4000 \mathrm{~g}$ and 40-41 weeks for singletons, 2500-2800 $\mathrm{g}$ and 36-37 weeks for twins, and 1900-2200 $\mathrm{g}$ and $34-35$ weeks for triplets is $75-80 \%$ less than the respective plurality-specific overall rates. Even at immature gestational ages, adequate intrauterine growth is consistently associated with substantial reductions in the risk of fetal death, regardless of plurality. The similarity in all fetal deaths, with the 50\% distribution occurring under $1900 \mathrm{~g}$ and before 34 weeks, suggests a common etiology of growth retardation across all pluralities. These findings confirm previous reports that intrauterine growth retardation is associated with an increased risk of fetal and neonatal death $[4,7,8,15,20,30]$, as well as higher rates of morbidity among survivors, regardless of plurality $[12,13,18]$. This analysis also confirms and extends the first phase of this study, which demonstrated that the lowest fetal mortality occurs at an earlier gestational age and lower birthweight for twins compared to singletons [15].

Infants of multiple gestations also achieve maturity at an earlier gestational age and lower birthweight compared to singletons. This analysis demonstrates that the singleton range of birthweight and gestational age maturity is actually postmature for twins and triplets, and if applied strictly to these pregnancies, results in a significantly higher incidence of fetal death among multiples. At the singleton ideal gestational age, 40-41 weeks, the risk of fetal death is 6.5 -fold higher for twins and 48.1 -fold higher for triplets. Conversely, at the twin ideal birthweight and gestational age, 2500-2800 g and 36-37 weeks, the fetal death rate for singletons is two-fold higher (6.5 vs 3.3), and at the triplet ideal birthweight and gestational age, 1900-2200 $\mathrm{g}$ and 34-35 weeks, the fetal death rate for singletons is 5.3 -fold higher (27.8 vs 5.2). Other researchers have shown that fetal lung maturation occurs several weeks earlier for twins than singletons [10], and that even at very low birthweights and immature gestational ages (500-1499 g at 28-31 weeks) twins have a significantly lower incidence of bronchopulmonary dysplasia [29]. Although there is a need to supplement this current population-based analysis with clinical studies to determine the subsequent postnatal risk of prematurity-related morbidity among twins and triplets born at these "ideal" birthweight and gestational ages, current evidence suggests that this weight for age is associated with a good outcome.

In multiple births there are also a variety of unique factors known to increase the risk for fetal death that are not amenable to change, including placental vascular anastomoses, cord complications, and congenital anomalies, as well as a higher incidence of such complications as anemia, hemorrhage, and premature rupture of membranes. Current therapies to improve birthweight or prolong gestation in multiple births, including hospitalization [3, 21] and prophylactic tocolysis have not been consistently effective. Maternal weight gain, on the other hand, is strongly associated with enhanced birthweights for gestational ages in singletons [6] as well as twins $[1,11,13,16,17,19]$. Preliminary studies in triplet gestations indicate that maternal weight gain may have an even greater positive effect on the birthweight of these high-risk infants [16].

There are several limitations of this study: this analysis did not consider the dependent nature of sibships among infants of multiple gestations, discordancy, infant race or 
gender, or antenatal or intrapartum complications. These factors will be considered in the third and final component of this study. Despite these limitations, this study represents the first series of population-based clinical guidelines for the management of multiple gestations.

\section{REFERENCES}

1. Brown JE, Schloesser PT (1990): Prepregnancy weight status, prenatal weight gain, and the outcome of term twin gestations. Am J Obstet Gynecol 162: 182-186.

2. Cherouny PH, Hoskins IA, Johnson TRB, Niebyl JR (1989): Muitiple pregnancy with late death of one fetus. Obstet Gynecol 74: 318-320.

3. Crowther CA, Verkuyl DM, Ashworth MF, Bannerman C, Ashurst HM (1991): The effects of hospitalization for bed rest on duration of gestation, fetal growth, and neonatal morbidity in triplet pregnancy. Acta Genet Med Gemellol 40: 63-68.

4. David RJ (1980): The quality and completeness of birthweight and gestational age data in computerized birth files. Am J Public Health 70: 964-973.

5. Elster AD, Bleyl JL, Craven TE (1991): Birth weight standards for triplets under modern obstetric care in the United States, 1984-1989. Obstet Gynecol 77: 387-393.

6. Food and Nutrition Board. Nutrition During Pregnancy. Washington, DC: National Academy of Science, 1990.

7. Kiely JL, Kleinman JC, Kiely M (1992): Triplets and higher-order multiple births. Am J Dis Child 146: 862-868.

8. Kilpatrick SJ, Jackson R, Croughan-Minihane MS (1996): Perinatal mortality in twins and singletons matched for gestational age at delivery at $>30$ weeks. Am J Obstet Gynecol 174: 66-71.

9. Kovacs BW, Kirschbaum TH, Paul RH (1989): Twin gestations: I. Antenatal care and complications. Obstet Gynecol 74: 313-317.

10. Leveno KJ, Quirk JG, Whalley PJ, Herbert WN, Trubey R (1984): Fetal lung maturation in twin gestation. Am J Obstet Gynecol 148: 405- 411.

11. Luke B, Minogue J, Abbey H (1992): The association between maternal weight gain and the birthweight of twins. J Maternal-Fetal Med 1: 267-276.

12. Luke B, Minogue J, Witter FR (1993): The role of fetal growth restriction and gestational age on length of hospital stay in twin infants. Obstet Gynecol 81: 949-953.

13. Luke B, Minogue J, Witter FR, Keith LG, Johnson TRB (1993): The ideal twin pregnancy: Patterns of weight gain, discordancy, and length of gestation. Am J Obstet Gynecol 169: 588-597.

14. Luke B (1994): The changing pattern of multiple births in the United States: Maternal and infant characteristics, 1973 and 1990. Obstet Gynecol 84: 101-106.

15. Luke B, Minogue $\mathbf{J}$ (1994): Contribution of gestational age and birth weight to perinatal viability in singletons versus twins. J Maternal-Fetal Med 3: 263-274.

16. Luke B, Bryan E, Sweetland C, Leurgans S, Keith L (1995): Prenatal weight gain and the birthweight of triplets. Acta Genet Med Gemellol 44: 93-101.

17. Luke B, Leurgans S (1996): Maternal weight gains in ideal twin outcomes. J Am Dietet Assoc 96: 178-181.

18. Luke B, Bigger H, Leurgans S, Sietsema D (1996): The cost of prematurity: A case-control study of twins versus singletons. Am J Public Health 86: 809-814.

19. Pederson AL, Worthington-Robert B, Hickok DE (1989): Weight gain patterns during twin gestation. J Am Dietet Assoc 89: 642-646.

20. Piper JM, Xenakis E M-J, McFarland M, Elliott BD, Berkus MD, Langer O (1996): Do growth-retarded premature infants have different rates of perinatal morbidity and mortality than appropriately grown premature infants? Obstet Gynecol 87: 169-174.

21. Rhydstrom H, Nordenskold F, Grennert L, Ohrlander S, Aberg A (1987): Routine hospital care does not improve prognosis in twin gestation. Acta Obstet Gynecol Scand 66: 361-364. 
22. Seoud MAF, Toner JP, Kruithoff C, Muasher SJ (1992): Outcome of twin, triple, and quadruplet in vitro fertilization pregnancies: the Norfolk experience. Fertil Steril 57: 825-834.

23. Society for Assisted Reproductive Technology. Assisted reproductive technology in the United States and Canada (1993): 1991 results from the Society for Assisted Reproductive Technology generated from the American Fertility Society Registry. Fertil Steril 59:956-962.

24. US Department of Health, Education, and Welfare. Vital Statistics of the United States, 1970. Vol. I, Natality. HRA Pub. No. 75-1100. Rockville, MD, 1975.

25. US Department of Health and Human Services, Public Health Service. Vital Statistics of the United States, 1985. Vol. I, Natality. Hyattsville, MD, 1988.

26. Ventura SJ, Martin JA, Taffel SM, Advance report of final natality statistics, 1994. Monthly vital statistics report. Vol. 44, No. II, Suppl. Hyattsville, MD: National Center for Health Statistics, 1996.

27. Wilcox AJ, Skjoerven R (1992): Birth weight and perinatal mortality: The effect of gestational age. Am J Public Health 82: 378-382.

28. Wilcox LS, Mosher WD (1993): Use of infertility services in the United States. Obstet Gynecol 82: $122-127$.

29. Wolf EJ, Vintzileos AM, Rosenkrantz TS, Rodis JF, Lettieri L, Mallozzi A (1992): A comparison of pre-discharge survival and morbidity in singleton and twin very low birth weight infants. Obstet Gynecol 80: 436-439.

30. Zhang J, Bowes WA (1995): Birth-weight-for-gestational-age patterns by race, sex, and parity in the United States population. Obstet Gynecoh 86: 200-208.

Correspondence: Barbara Luke, ScD, MPH, Department of Obstetrics and Gynecology, University of Michigan Medical School, 1500 East Medical Center Drive, Ann Arbor, Michigan 48109-0264, USA. 